\title{
COVID-19 Preventive Behavior Practices and Determinants: A Scoping Review
}

\author{
Lely Lusmilasari $^{1 *}$ (D) Alenda Dwiadila Matra Putra ${ }^{2}$ D, Ayyu Sandhi ${ }^{1}$, Azam David Saifullah ${ }^{3}$ D \\ ${ }^{1}$ Department of Pediatric and Maternity Nursing, Faculty of Medicine, Public Health and Nursing, Universitas Gadjah Mada, \\ Yogyakarta, Indonesia; ${ }^{2}$ Challengers' Committee, Nursing Now Challenge, South-East Asia Regional Hub, Yogyakarta, \\ Indonesia; ${ }^{3}$ Department of Mental Health and Community Nursing, Faculty of Medicine, Public Health and Nursing, Universitas \\ Gadjah Mada, Yogyakarta, Indonesia
}

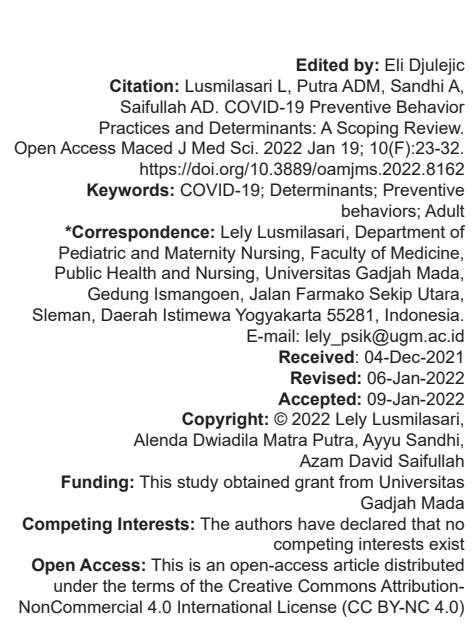

Introduction

Since early 2020, the global community has been battling a pandemic caused by coronavirus disease, known as COVID-19. This disease, which affects both the adult population and the respiratory system of children, has become widespread in countries [1]. With respect to this situation, the World Health Organization (WHO) has declared the SARS-CoV-2 epidemic a global public health emergency since March 2020. The WHO reported that there were $260,493,573$ confirmed cases, with more than 5 million deaths by November 28, 2021 [2].

The COVID-19 pandemic is resulting in enormous drawbacks as the number of morbidity and mortality has surged since the pandemic hit the global community hard. Saladino et al. [3] strongly revealed that psychological and social issues have significantly occurred amidst the pandemic. What is more, people experience the feeling of being separated from relatives and helplessness, loss of freedom, and uncertainties related to disease development [4], [5].
Preventive behaviors which can reduce the transmission of COVID-19 play an important role amidst the pandemic. Disease prevention behavior is a reaction to prevent the onset of the disease [6]. The COVID-19 preventive behavior is defined as measures to suppress the transmission of COVID-19. Several measures recommended by the government, such as social/physical distancing, self-isolation and quarantine, lockdown, and other measures have been performed as mass prevention strategies. These strategies are conducted in order to stop the infection-related pandemic [7]. According to CDC [8] and WHO [9], the COVID-19 preventive behavior comprises avoiding to touch eyes, nose, and mouth, washing hand with soap and water or alcohol-based liquid regularly, performing cough etiquette or respiratory hygiene, social or physical distancing, self-isolating if feeling ill, avoiding crowds, and maintaining distance from people who are sick. Other related behaviors to prevent COVID-19 transmission include consuming nutritious food, exercising regularly, and receiving COVID-19 immunizations [10].

Preventing the transmission of COVID-19 requires compliance with preventive behavior by local 
governments and the local community as the virus is easily transmitted in humans. This virus is transmitted by droplets from the nose and mouth of patients, through contact, fomite and fecal-oral contact [11], [12]. Therefore, the COVID-19 preventive behavior cannot be conducted without active participation of society [13]. Each community member has to regularly perform the COVID-19 preventive behavior to control the virus spreading amidst the pandemic.

The implementation of behavior is influenced by several factors, according to LaMorte [14] is effectively performed if obstacles, benefits, threats, the willingness to act as well as self-efficacy is acknowledged by people. This is explained that individuals will take preventive action when one is aware of the susceptibility of a certain situation (perceived susceptibility), perception of the worst condition might happen (perceived severity), the understandings of loss reduction (perceived benefit), and perception of negative effect related to health (perceived barriers) [15]. Therefore, an evaluation to assess the COVID-19 preventive behavior is essentially needed as a component in monitoring and developing an intervention based on community needs.

Since the start of the global COVID-19 pandemic in 2019, preventive behaviors have been widely applied regardless of the sociocultural, economic, and educational status of individuals. However, studies related to its implementation have not been completely reviewed to identify the behavior that is obedient as well as the determining factors for its implementation. According to this emerging situation, authors are intrigued to explore the implementation behavior of COVID-19 prevention among people across countries.

\section{Methods}

As the topic of COVID-19 preventive behaviors has not been comprehensively reviewed, this study employed a scoping approach to synthesize evidence from existing studies about the implementation of COVID-19 preventive behaviors, its determinants, and its measurement tools following the guidelines by a: (1) Formulation of the research question(s), (2) identification of relevant studies, (3) study selection, (4) charting the data, and (5) collating, summarizing, and reporting the results. To assess the methodological quality of selected studies and to determine the extent to which selected studies have addressed the possibility of bias, critical appraisal was performed individually by four authors using Joanna Briggs Institute Critical appraisal tools [16].

\section{Research questions}

This scoping review determined three research questions. These research questions were: (1) "How was COVID-19 preventive behaviors described?" (2) "What are the determinants of COVID-19 preventive behaviors?" and (3) "What are the measurement tools of COVID-19 preventive behaviors?"

\section{Search methods}

Five electronic databases (Scopus, ScienceDirect, SAGE Journals, ProQuest, and EBSCOhost) had been searched to retrieve relevant studies. Keywords of (adult OR family OR "informal caregiver") AND ("preventive behavior" OR "preventive behavior" OR prevention OR "preventive practice") AND (pandemic OR covid-19) were applied to identify studies published between January 2019 and August 2021 with free full-text availability in English.

\section{Eligibility criteria}

Studies were included if those were original studies employing quantitative, qualitative, or theoretical design; involving adults or family members older than 18 years of age only who performed COVID-19 preventive behaviors; and published in peer-reviewed journals. Studies were excluded if preventive behaviors were described in a general context (not related to COVID-19 pandemic) and no description of socio-demographic characteristics of participants.

\section{Screening}

There were 875 studies identified, of which 120 studies were duplicates. Two authors (LL and ADMP) then independently screened 755 studies by title and abstract. After screening by title and abstract, the full texts of 39 studies were assessed for eligibility. After screening the full text, 27 studies were found to meet the objectives of this scoping review.

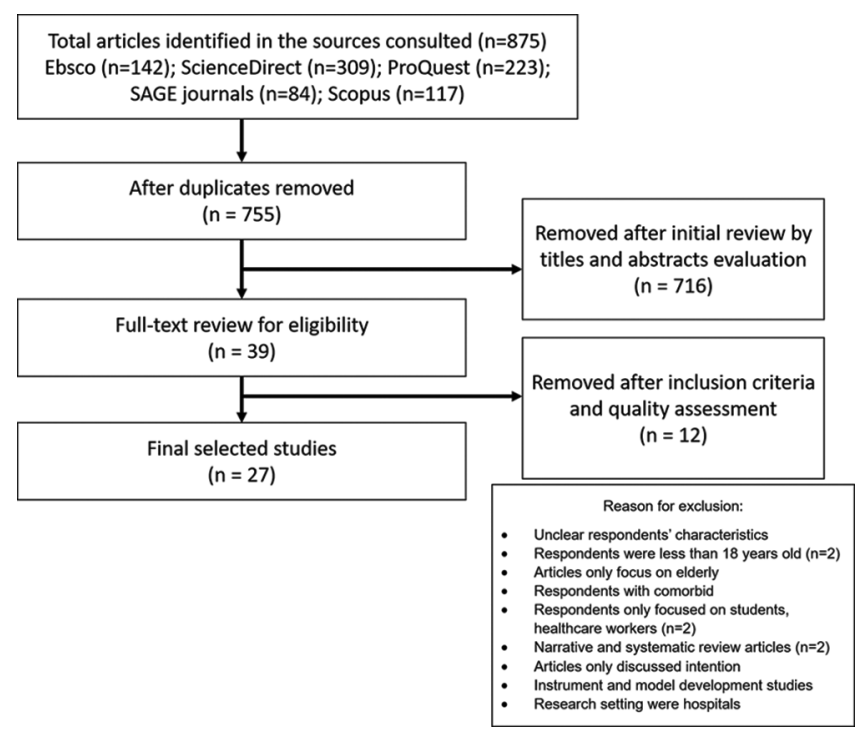

Figure 1: PRISMA flow diagram 


\section{Data extraction}

Data extraction was conducted by four authors in an Excel spreadsheet to identify the following information from selected studies such as author, publication date (year), country, participants, design, determinants factors to COVID-19 preventive measures, implementation of COVID-19 preventive measures, and instrument used. A data charting table was created to identify themes from study findings which correspond to research objectives and questions [17].

\section{Data analysis}

Data analysis was performed by four authors who summarized the major findings from selected studies to draw themes and subthemes independently [17]. The authors then merged the data analysis and performed joint analysis to determine the sub-themes of research questions.

\section{Results}

After following the article screening guideline, 27 articles were included in this review article. Almost half of the selected studies were conducted in Asian countries: Iran (3 studies), Saudi Arabia (3 studies), one study in Taiwan, Vietnam, Malaysia, Korea, and Hong Kong, followed by African countries with Egypt (3 studies), Ethiopia (2 studies), one study from Cameroon, Malawi, and Kenya. The remaining studies were from European countries with one study each: Germany, Slovenia, and Hungary. Furthermore, two studies from the USA, one study from Brazil and Mexico can be seen in Table 1. In addition, 26 of 27 selected articles used cross-sectional research design and only a study using a three-wave prospective correlational design. Furthermore, Table 1 also presents the summary of every selected study including determinant factors and the implementation of COVID-19 preventive measures.

Turning to the analytical and synthesis findings of the selected articles, this review deduced two main themes, namely implementation and determinant factors of COVID-19 preventive behaviors. Moreover, four sub-themes were identified to describe the preventive behaviors implementation as seen in Table 2, namely: (1) Personal preventive measures, (2) community preventive measures, (3) immune boosting, and (4) self-screening and medication. In addition, (1) socio-demographic factors, (2) social psychological factors, (3) health status factors, and (4) enabling factors were obtained as the sub-themes of determinant factors of COVID-19 preventive measures as seen in Table 3.

\section{Implementation of preventive measures}

Most of the authors of the selected studies used self-developed questionnaires to identify the implementation of COVID-19 preventive behaviors. All instruments were developed from literature or previous study and/or combining with the WHO guidelines [18], [19], [20], [21], [22] and CDC guidelines [22], [23], H1N1 epidemic [24], HIV-related surveys [25], [26], SARrelated study [13], and each Ministry of Health $(\mathrm{MOH})$ guideline in each country [19], [20], [21], [22]. Moreover, only eight authors presented reliability scores of their instruments [18], [26], [27], [28], [29], [30], [31], [32] and the remaining did not provide clear information about psychometric testing.

\section{Personal preventive measures}

Personal preventive measures which were well-practiced by most respondents in the selected studies are: regular handwashing [13], [19], [20], [21], [22], [23], [25], [29], [30], [31], [32], [33], [34], [35], [36], [37], [38], [39], [40], [41], [42] except Yehualashet et al. [26], wearing face masks [13], [19], [21], [22], [23], [24], [29], [30], [31], [34], [35], [36], [38], [39], [40], [41] except 4 studies [26], [33], [37], [42], cough/sneeze etiquette [13], [20], [22], [23], [24], [26], [29], [30], [32], [34], [36], [40], [41] except Faria de Moura Villela et al. [37], physical/social distancing [13], [21], [22], [23], [24], [29], [30], [31], [33], [34], [35], [37], [38], [40] except three studies [20], [26], [42], using hand sanitizer [13], [21], [23], [24], [31], [34], [36], [37] [38] except Gutu et al. [20] and Yehualashet et al. [26], avoid touch face [13], [23], [24], [29], [32], [34], [37], [38], [40], [41] except four studies [20], [26], [30], [42], avoid handshake [19], [20], [21], [29], [32], [38], [42] except Ali et al. [30], disinfect personal belongings [13], [29], [37] except [26], [34], [40], maintain ventilation [13], [29], [40], avoid contact with animals [29], and dispose used PPS in a hygienic manner [29]. On the other hand, regular body temperature [34], [37], wearing gloves when leaving home [19], [40], [42], separate use of clothing inside and outside home [40], and regular replacement of masks and gloves [40] were poorly adopted by respondents.

\section{Community preventive measures}

Community preventive measures which were well-performed by respondents are reported as follows: avoid crowded place/public spaces [13], [21], [22], [24], [25], [29], [30], [33], [34]. [35], [36], [38], [39], [40], [41] except two studies [36], [40], avoid meetings [13], [21], [33], [34], [38], [40], [42] except one study [31], staying at home [13], [21], [22], [23], [24], [29], [30], [32], [36], [38], [41], [42] except three studies [26], [33], [35], avoid public transportation [21], [34], [36], [38], [42], avoid contact with infected/vulnerable person [21], [30], [36], [41], [42] except one study [40], avoid travelling [13], 


\section{Table 1: Summary of selected studies}

\begin{tabular}{|c|c|c|c|c|}
\hline Author and Country & Sample & Design & $\begin{array}{l}\text { Determinants factors of COVID-19 } \\
\text { Preventive Measures }\end{array}$ & $\begin{array}{l}\text { Implementation of COVID-19 } \\
\text { Preventive Measures }\end{array}$ \\
\hline $\begin{array}{l}\text { Lin et al., } 2020 \\
\text { Iran }\end{array}$ & $\begin{array}{l}1563 \text { Iranian adults } \\
\text { aged } 18 \text { years and } \\
\text { older }\end{array}$ & $\begin{array}{l}\text { Three-wave } \\
\text { prospective } \\
\text { correlational }\end{array}$ & $\begin{array}{l}\text { Intention, coping planning, action } \\
\text { planning, maintenance, self-efficacy, } \\
\text { perceived behavioral control }\end{array}$ & $\mathrm{N} / \mathrm{l}$ \\
\hline $\begin{array}{l}\text { Lin and Chen, } 2021 \\
\text { Taiwan }\end{array}$ & $\begin{array}{l}1012 \text { LINE users in } \\
\text { Taiwan }\end{array}$ & Cross-sectional & Fear arousal, age, gender & $\mathrm{N} / \mathrm{I}$ \\
\hline $\begin{array}{l}\text { Lüdecke and von } \\
\text { dem Knesebeck, } \\
2020 \\
\text { Germany }\end{array}$ & $\begin{array}{l}3186 \text { Germans aged } \\
18 \text { years and older }\end{array}$ & Cross-sectional & education level and gender & $\begin{array}{l}\text { Majority of respondents obeyed to } \\
\text { perform handwashing, avoid crowded } \\
\text { places, reduce meetings, do physical } \\
\text { distancing, and use disinfectant. While } \\
\text { they did not regularly practice to adapt } \\
\text { school or work situation, stay at home, } \\
\text { and wear face masks }\end{array}$ \\
\hline
\end{tabular}

Mirzaei et al., $2021 \quad 558$ Iranian adults (18 Cross-sectional Perceived benefit, perceived Iran years or older) from 24 provinces across the country

Nguyen et al., $2020 \quad 2175$ Vietnamese Vietnam citizen (18 years or older)

Ngwewondo et al., 1006 Cameroonian 2020 Cameroon or older)

Cross-sectional Perceived adaptation of the community to lockdown, fear student

Cross-sectional Age and women residing in large cities, access to official COVID-19 information, working in healthcare/medical

Nourmoradi, et al 2020

Iran

Ali et al., 2021

Egypt

731 adult Egyptian community $(\geq 18$ year old)

Alkhaldi et al., 2021 Saudi Arabia

2393 Saudi Arabian respondents (18 year old and above)

Almoayad et al., 2021847 residents of Saudi Arabia Riyadh city who wer over 18 years of age

Aschwanden et al., 2256 participants from Cross-sectional older adult 2021 every US state and The United States of Washington as well America as Puerto Rico, age range $18-98$ year old

Bachok et al., $2021 \quad 1290$ participants from Cross-sectional ethnicity and marital status Malaysia 14 Malaysian states
Cross-sectional elderly, female, healthcare practitioners of COVID-19

younger age, higher education, masks, forget and not accustomed push, financial barriers, and unavailability of mask and sanitizer

Cross-sectional lowest income$$
\text { practitioners }
$$

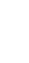


Table 1: (Continued)

\begin{tabular}{lllll}
\hline Author and Country & Sample & Design & $\begin{array}{l}\text { Determinants factors of COVID-19 } \\
\text { Preventive Measures }\end{array}$ & I \\
& & & Pro \\
\hline $\begin{array}{l}\text { Banda et al., 2021 } \\
\text { Malawi }\end{array}$ & $\begin{array}{l}\text { 619 respondents of } \\
\text { Malawi resident }\end{array}$ & Cross-sectional & $\mathrm{N} / \mathrm{l}$ & Onl
\end{tabular}

Instruments

Preventive Measures

Malawi Malawi resident

A self developed questionnaire

crowds were well-adopted by both administered by phone interviews.

respondents in rural and urban areas. Questionnaires were adapted from

instruments used in previous study and HIV-related surveys. There is no clear information regarding the expert review,

Barakat and Kasemy, 182 Egyptians 2020

Egypt

Bazaid et al., 2020 Saudi Arabia

5105 Saudi residents aged 18 years and older

Ethiopia

Faria de Moura

Villela et al., 2021 Brazil

Karijo, 2021

2156 youth (aged

Kenya

18-35) in Kenya

Kim and Kim, 2020 Korea population aged 18 years and older

634 adults from urban in Ethiopia (aged 18 and older)

A community based Cros sectional

Knowledge about COVID-19, urban and rural areas, and social media use

age, high education, healthcare worker, perceived susceptibility, perceived benefit, perceived barriers, and ability to follow the preventive measures against the disease

Female, high socioeconomic stu
high level of education, youth, resident of the northern part of the KSA

23.896 adults ( 18 and Survey Study older) living in Brazil

Survey Study

Younger people, male, living in rural area, student, and workers

Cross-sectional Women, age, number of elderly in family, perceived severity, perceived benefit, self-efficacy, good family health, media exposure, knowledge, personal health status, and social support
Lee et al., 2021 Korea

970 Korean aged 18 years or older

Cross-sectional knowledge, efficacy belief, lack of access to healthcare, and preexisting health condition

67 families with at least one farmworker (FWF) and 38 comparable families with no farmworkers (nonFWF) in North Carolina

Sánchez-Arenas 1030 participants et al., 2021

Mexico

Cross-sectional N/I

Cross-sectional female, older age, professional worker, homemaker, retiree, regular physical exercise, high health literacy, and access to COVID-19 information, perceived severity and perceived effectiveness

Smail et al., 2021 4445 respondents The United States of

America

Turk et al., $2021 \quad 2467$ participants Slovenia
All 8 preventive behaviors were wellperformed by respondents over the three periods of time validity, or reliability of the questionnaire. Questionnaire by personal interviews and online (Google Form). The questionnaire has a good reliability as Cronbach's alpha has been calculated, and it was 0.83 .

Avoid handshaking, practicing masks questionnaire that was created were the most common practices by according to the Saudi MOH and WHO respondents. guidelines to measure the knowledge and commitment of the Saudi public. There is no clear information regarding the expert review, validity, or reliability of the questionnaire.

Avoid contact greetings, cook meat and eggs before eating, and regular hand washing were the most often preventive behavior adoptions conducted by respondents. However, other measures were poorly performed Physical distancing, cough etiquette, regular handwashing, using hand sanitizer, avoiding touch face, and disinfecting phones were regularly performed by respondents to prevent COVID-19 infection. Wearing face masks, checking body temperature, and avoid travelling were not obeyed by respondents

Respondents adopted almost all preventive measures regularly, however, only $45.7 \%$ of them were keen to voluntarily test themselves to know their COVID-19 status.

Respondents of the study wellcomplied with all 19 preventive measures assessed in this study

A self developed questionnaire based on the preventive behavior recommendation of $\mathrm{WHO}$ and $\mathrm{MOH}$ to reduce the spread of COVID-19. There is no clear information regarding the expert review, validity, or reliability of the questionnaire. A self developed online questionnaire survey. There is no clear information regarding the expert review, validity, or reliability of the questionnaire.

An online questionnaire including set of 40 questions were adopted from previous COVID-19 related studies in Kenya. There is no clear information regarding the expert review, validity, or reliability of the questionnaire.

A self developed questionnaire that was designed based on previous studies on SARS and COVID-19. The most important questions were those measuring the preventive behaviors recommended by the government, the $\mathrm{WHO}$, and other scientific organizations. There is no clear information regarding the expert review, validity, or reliability of the questionnaire.

This study only assessed 3 preventice A self-developed questionnaire practices, they were wearing face measuring precautionary behavior masks, practicing hand hygiene, practices that covered the following and avoiding crowded places, all of two categories: preventive measures which were well-performed by the and social distancing. There is no clear respondents information regarding the expert review, validity, or reliability of the questionnaire. Avoiding travelling, handwashing, avoid $\begin{aligned} & \text { validity, or reliability of the question } \\ & \text { Selfeveloped Questionnaire to }\end{aligned}$ eating outside of the house, staying at measure personal behaviors to protect home when sick, avoiding close contact, health and prevent spread of the avoiding crowds, and wearing face coronavirus in the past month. There masks were the preventive measures is no clear information regarding the which were well-practiced by both expert review, validity, or reliability of the farmworkers and non-farmworkers questionnaire.

15 of 18 preventive behaviors were A self developed questionnaire based well-performed by the respondents on the World Health Organization (WHO) and the Mexican government's recommendations on preventive measures of COVID-19. There is no clear information regarding the expert review, validity, or reliability of the questionnaire.

Self-developed Questionnaire to measure voluntary preventive behaviors on COVID-19. There is no clear information regarding the expert review, validity, or reliability of the questionnaire. Self-developed Questionnaire based on health guidelines related to COVID-19.

11 of 25 suggested behavior to prevent COVID-19 transmission were performed by more than $50 \%$ of There is no clear information regarding respondents

the expert review, validity, or reliability of the questionnaire. 
Table 1: (Continued)

\begin{tabular}{|c|c|c|c|c|c|}
\hline Author and Country & Sample & Design & $\begin{array}{l}\text { Determinants factors of COVID-19 } \\
\text { Preventive Measures }\end{array}$ & $\begin{array}{l}\text { Implementation of COVID-19 } \\
\text { Preventive Measures }\end{array}$ & Instruments \\
\hline $\begin{array}{l}\text { Urbán et al., } 2021 \\
\text { Hungary }\end{array}$ & $\begin{array}{l}5254 \text { adult age } \\
\text { residing in Hungary }\end{array}$ & Cross-sectional & Gender and age & $\begin{array}{l}\text { Most of the respondents performed } 8 \\
\text { of } 15 \text { COVID-19 prevention behaviors } \\
\text { regularly in this study }\end{array}$ & $\begin{array}{l}\text { Self-developed questionnaire to measure } \\
\text { preventive behaviors. There is no clear } \\
\text { information regarding the expert review, } \\
\text { validity, or reliability of the questionnaire. }\end{array}$ \\
\hline $\begin{array}{l}\text { Wong et al., } 2020 \\
\text { Hong Kong }\end{array}$ & $\begin{array}{l}501 \text { randomly selected } \\
\text { Chinese adults in } \\
\text { Hong Kong }\end{array}$ & Cross-sectional & $\begin{array}{l}\text { COVID-19 information sharing with } \\
\text { family member, individual health } \\
\text { literacy, and family well-being }\end{array}$ & $\begin{array}{l}\text { Regular hand washing and wearing } \\
\text { masks were the most abided } \\
\text { preventive measures in this study } \\
\text { among other measures }\end{array}$ & $\begin{array}{l}\text { Self-developed questionnaire to measure } \\
\text { preventive behaviors against COVID- } 19 \text {. } \\
\text { Its internal consistency was satisfactory } \\
\text { with Cronbach's alpha } 0.72 \text {. }\end{array}$ \\
\hline $\begin{array}{l}\text { Yehualashet et al., } \\
2021 \\
\text { Ethiopia }\end{array}$ & $\begin{array}{l}683 \text { respondents, } \\
\text { North Shoa zone, } \\
\text { Amhara regional state, } \\
\text { Ethiopia }\end{array}$ & Cross-sectional & $\begin{array}{l}\text { Perceived susceptibility and } \\
\text { perceived barriers }\end{array}$ & $\begin{array}{l}\text { Covering mouth and nose when } \\
\text { coughing or sneezing was the only } \\
\text { sufficiently-performed behavior with } \\
57.9 \% \text { of respondents among other } \\
\text { behaviors. }\end{array}$ & $\begin{array}{l}\text { Self-developed questionnaire adopted } \\
\text { from a WHO survey tool for COVID-19 } \\
\text { (from HIVIAIDS). The questionnaire has } \\
\text { a Cronbach alpha of } 0.68 \text {. }\end{array}$ \\
\hline
\end{tabular}

[29], [34], [36], [37], [38], [41] except one study [20], adapting school/work situation [21], [36] except one study [33], disinfecting surroundings [13], [21], [22], [23], [29], [30], [33], [36], [38], [41] except three studies [26], [31], [40] and avoiding using common plates with strangers [34].

\section{Immune boosting}

With respect to immune boosting importance, there were five articles exploring this preventive behavior. Immune boosting measures are related to consuming diet and lifestyle modification to improve the immune system during the pandemic. Participants showed good preventive practices such as taking vitamins [13], [35], maintaining a healthy diet [13], and cooking meat and eggs [20]. One study enlists that smoking was still performed by the participants [29].

\section{Self-screening and medications}

Self-screening and medication behavior to prevent COVID-19 transmission were poorly practiced by respondents in all studies assessing these measures. Ngwewondo et al. reported a very few respondents took traditional medicine, chloroquine, and paracetamol/ ibuprofen as preventive measures [35]. In addition, getting tested for COVID-19 [38] and assessing COVID-19 risk using government web applications [21] were still not popular among residents.

\section{Determinant factors}

\section{Socio-demographic factors}

There were 17 studies which found 15 factors to COVID-19 preventive measures according to sociodemographic characteristics. The most frequent reported factor by 13 authors was age [13], [19], [21], [22], [23], [27], [30], [32], [35], [37], [40], [42], [43], followed by gender which were presented in 12 studies [13], [19], [21], [22], [27], [30], [33], [35], [37], [40], [42], [43], education level [19], [30], [32], [33], [40], [43], occupation [20], [21], [31], [33], [36], [39], marital status [24], ethnicity [24], [43], socioeconomic status [19], [30], [36], residential area [19], [20], [34], [37] and settlement size [40].

\section{Social psychological factors}

Six-related studies revealed that perceived severity was related to COVID-19 preventive behaviors [13], [21], [27], [29], [34], [43]. In addition, perceived barriers [26], [28], [30], [32], perceived benefits [13], [28], [32], [34], perceived susceptibility [26], [32], [43], self-efficacy and maintenance [13], [18], [21], [28], [39], [43] and knowledge about COVID-19 [13], [20], [31], [39] were also the determinant factors associated with preventive measures. What is more, Lin et al. presented that intention, coping planning, and action planning were the additional factors related to the preventive measures [18].

\section{Health status factors}

This review article found that health status is associated with the adherence of COVID-19 preventive behaviors. Three authors displayed family health status [13], [31], [40] and three authors presented personal health status [13], [21], [39] as the part of the determinant factors.

\section{Enabling factors}

Enabling factors is external stimulus influencing one's preventive behavior. There are six factors associated with COVID-19 preventive measures as the element of enabling factors. These factors include lack of governmental push [30], media exposure [13], [20], access to information [31], [34], access to PPE [29], access to healthcare [39], and social support [13].

\section{Discussion}

The COVID-19 pandemic which has lasted for almost two years is an impactful health crisis for millions of people worldwide. Every country has put many efforts to improve the COVID-19 preventive behavior compliance to reduce the transmission of the virus. Health prevention behavior is a response to prevent diseases including activity undertaken by a person 
Table 2: The findings of COVID-19 preventive measures implementation

\begin{tabular}{|c|c|c|}
\hline Preventive Measures & Good Practice Findings & Poor Practice Findings \\
\hline \multicolumn{3}{|l|}{ Personal Preventive Measures } \\
\hline Regular handwashing & $\begin{array}{l}\text { Lüdecke and von dem Knesebeck, 2020; Nguyen et al., 2020; Ngwewondo et al., 2020; } \\
\text { Nourmoradi et al., 2020; Ali et al., 2021; Alkhaldi et al., 2021; Almoayad et al., 2021; } \\
\text { Aschwanden et al., 2021; Banda et al., 2021; Barakat and Kasemy 2020; Bazaid et al., } \\
\text { 2020; Gutu et al., 2021; Faria de Moura Villela et al., 2021; Karijo 2021; Kim and Kim } \\
\text { 2020; Lee et al., 2021; Quandt et al., 2020; Sánchez-Arenas et al., 2021; Turk et al., 2021; } \\
\text { Urbán et al., 2021; Wong et al., } 2020\end{array}$ & Yehualashet et al., 2021 \\
\hline Wear face masks & $\begin{array}{l}\text { Nguyen et al., 2020; Ngwewondo et al., 2020; Nourmoradi et al., 2020; Ali et al., 2021; } \\
\text { Alkhaldi et al., 2021; Almoayad et al., 2021; Aschwanden et al., 2021; Bachok et al., 2021; } \\
\text { Bazaid et al., 2020; Karijo 2021; Kim and Kim 2020; Lee et al., 2021; Quandt et al., 2020; } \\
\text { Sánchez-Arenas et al., 2021; Turk et al., 2021; Wong et al., } 2020\end{array}$ & $\begin{array}{l}\text { Lüdecke and von dem Knesebeck, 2020; } \\
\text { Faria de Moura Villela et al., 2021; Urbán } \\
\text { et al., 2021; Yehualashet et al., } 2021\end{array}$ \\
\hline Cough/sneeze etiquette & $\begin{array}{l}\text { Nguyen et al., 2020; Nourmoradi et al., 2020; Ali et al., 2021; Alkhaldi et al., 2021; } \\
\text { Almoayad et al., 2021; Aschwanden et al., 2021; Bachok et al., 2021; Barakat and } \\
\text { Kasemy 2020; Gutu et al., 2021; Kim and Kim 2020; Quandt et al., 2020; Sánchez-Arenas } \\
\text { et al., 2021; Turk et al., 2021; Yehualashet et al., } 2021\end{array}$ & Faria de Moura Villela et al., 2021 \\
\hline Physical/social distancing & $\begin{array}{l}\text { Lüdecke and von dem Knesebeck, 2020; Nguyen et al., 2020; Ngwewondo et al., 2020; } \\
\text { Nourmoradi et al., 2020; Ali et al., 2021; Almoayad et al., 2021; Aschwanden et al., 2021; } \\
\text { Bachok et al., 2021; Faria de Moura Villela et al., 2021; Karijo 2021; Kim and Kim 2020; } \\
\text { Sánchez-Arenas et al., 2021; Turk et al., 2021; Wong et al., 2020; Karijo } 2021\end{array}$ & $\begin{array}{l}\text { Gutu et al., 2021; Urbán et al., 2021; } \\
\text { Yehualashet et al., } 2021\end{array}$ \\
\hline Use hand sanitizer & $\begin{array}{l}\text { Nguyen et al., 2020; Alkhaldi et al., 2021; Aschwanden et al., 2021; Bachok et al., 2021; } \\
\text { Faria de Moura Villela et al., 2021; Karijo 2021; Kim and Kim 2020; Sánchez-Arenas } \\
\text { et al., 2021; Wong et al., } 2020\end{array}$ & $\begin{array}{l}\text { Gutu et al., 2021; Yehualashet et al., et al., } \\
2021\end{array}$ \\
\hline Avoid touch face & $\begin{array}{l}\text { Nguyen et al., 2020; Nourmoradi et al., 2020; Aschwanden et al., 2021; Bachok et al., } \\
\text { 2021; Barakat and Kasemy 2020; Faria de Moura Villela et al., 2021; Karijo 2021; Kim and } \\
\text { Kim 2020; Quandt et al., 2020; Turk et al., 2021; }\end{array}$ & $\begin{array}{l}\text { Ali et al., 2021; Gutu et al., 2021; Urbán } \\
\text { et al., 2021; Yehualashet et al., } 2021\end{array}$ \\
\hline Avoid handshake & $\begin{array}{l}\text { Nourmoradi et al., 2020; Barakat and Kasemy 2020; Bazaid et al., 2020; Gutu et al., 2021; } \\
\text { Karijo 2021; Sánchez-Arenas et al., 2021; Urbán et al., } 2021\end{array}$ & Ali et al., 2021 \\
\hline Disinfect personal belongings & Nourmoradi et al., 2020; Faria de Moura Villela et al., 2021; Kim and Kim 2020 & $\begin{array}{l}\text { Nguyen et al., 2020; Turk et al., 2021; } \\
\text { Yehualashet et al., } 2021\end{array}$ \\
\hline Maintain ventilation & Nourmoradi et al., 2020; Kim and Kim 2020; Turk et al., 2021 & \\
\hline Avoid contact with animals & Nourmoradi et al., 2020; & \\
\hline $\begin{array}{l}\text { Dispose used PPE in a hygienic manner } \\
\text { Regular body temperature check }\end{array}$ & Nourmoradi et al., 2020; & $\begin{array}{l}\text { Nguyen et al., 2020; Faria de Moura Villela } \\
\text { et al., } 2021\end{array}$ \\
\hline $\begin{array}{l}\text { Wear gloves when contacting objects/leave } \\
\text { home }\end{array}$ & & $\begin{array}{l}\text { Bazaid et al., 2020; Turk et al., 2021; Urbán } \\
\text { et al., } 2021\end{array}$ \\
\hline Separate use of clothing inside and outside & & Turk et al., 2021 \\
\hline Regular replacement of masks and gloves & & Turk et al., 2021 \\
\hline \multicolumn{3}{|l|}{ Community Preventive Measures } \\
\hline $\begin{array}{l}\text { Avoid crowded place/public space (Avoid } \\
\text { eating outside home, Avoid social events) }\end{array}$ & $\begin{array}{l}\text { Lüdecke and von dem Knesebeck, 2020; Nguyen et al., 2020; Ngwewondo et al., 2020; } \\
\text { Nourmoradi et al., 2020; Alkhaldi et al., 2021; Bachok et al., 2021; Banda et al., 2021; } \\
\text { Karijo 2021; Kim and Kim 2020; Lee et al., 2021; Quandt et al., 2020; Sánchez-Arenas } \\
\text { et al., 2021; Almoayad et al., 2021; Turk et al., 2021; Ali et al., } 2021\end{array}$ & Turk et al., 2021; Alkhaldi et al., 2021 \\
\hline Stay at home & $\begin{array}{l}\text { Nourmoradi et al., 2020; Ali et al., 2021; Alkhaldi et al., 2021; Almoayad et al., 2021; } \\
\text { Aschwanden et al., 2021; Bachok et al., 2021; Barakat and Kasemy 2020; Karijo 2021; } \\
\text { Kim and Kim 2020; Quandt et al., 2020; Sánchez-Arenas et al., 2021; Urbán et al., } 2021\end{array}$ & $\begin{array}{l}\text { Lüdecke and von dem Knesebeck, 2020; } \\
\text { Ngwewondo et al., 2020; Yehualashet } \\
\text { et al., } 2021\end{array}$ \\
\hline Avoid public transportation & $\begin{array}{l}\text { Nguyen et al., 2020; Alkhaldi et al., et al., 2021; Karijo 2021; Sánchez-Arenas et al., 2021; } \\
\text { Urbán et al., } 2021\end{array}$ & \\
\hline Avoid contact with infected/vulnerable person & $\begin{array}{l}\text { Ali et al., 2021; Alkhaldi et al., 2021; Quandt et al., 2020; Sánchez-Arenas et al., 2021; } \\
\text { Urbán et al., } 2021\end{array}$ & Turk et al., 2021 \\
\hline Avoid travelling & $\begin{array}{l}\text { Nguyen et al., 2020; Nourmoradi et al., 2020; Alkhaldi et al., 2021; Faria de Moura Villela } \\
\text { et al., 2021; Karijo 2021; Kim and Kim 2020; Quandt et al., } 2020\end{array}$ & Gutu et al., 2021 \\
\hline Adapted school/work situation & Alkhaldi et al., 2021; Sánchez-Arenas et al., 2021 & Lüdecke and von dem Knesebeck, 2020 \\
\hline Avoid using common plates with strangers & Nguyen et al., 2020 & \\
\hline Disinfect surrounding & $\begin{array}{l}\text { Lüdecke and von dem Knesebeck, 2020; Nourmoradi et al., 2020; Ali et al., 2021; Alkhaldi } \\
\text { et al., 2021; Almoayad et al., 2021; Aschwanden et al., 2021; Karijo 2021; Kim and Kim } \\
\text { 2020; Quandt et al., 2020; Sánchez-Arenas et al., 2021; }\end{array}$ & $\begin{array}{l}\text { Turk et al., 2021; Wong et al., 2020; } \\
\text { Yehualashet et al., } 2021\end{array}$ \\
\hline \multicolumn{3}{|l|}{ Immunity boosting } \\
\hline Taking vitamin & Ngwewondo et al., 2020; Kim and Kim 2020 & \\
\hline Maintain healthy diet (Storing food & Kim and Kim 2020 & Nourmoradi et al., 2020; Urbán et al., 2021 \\
\hline $\begin{array}{l}\text { Cook meat and eggs well before eating } \\
\text { Avoid smoking }\end{array}$ & Gutu et al., 2021 & Nourmoradi et al., 2020; \\
\hline \multicolumn{3}{|l|}{ Self-screening and medications } \\
\hline Use of traditional concoctions & & Ngwewondo et al., 2020; \\
\hline Taking chloroquine & & Ngwewondo et al., 2020; \\
\hline Taking paracetamol//buprofen & & Ngwewondo et al., 2020; \\
\hline Get tested for COVID-19 & & Karijo 2021 \\
\hline $\begin{array}{l}\text { Assessing COVID-19 risk using government } \\
\text { web application }\end{array}$ & & Sánchez-Arenas et al., 2021; \\
\hline
\end{tabular}

who believes himself to be healthy for the purpose of preventing disease [44]. In terms of COVID-19 preventive behavior, the community is expected to abide by the international recommendations from WHO [45] such as washing your hands, wearing a face mask, and social distancing. The purpose of this review is to describe the implementation and the factors associated with COVID-19 preventive measures.

The results of the 27 selected studies show that there are four themes of COVID-19 preventive behavior implementation, namely personal preventive, community preventive, immune boosting, as well as self-screening and medication. The description of these behaviors was measured using various instruments. These instruments were developed by each author of the studies using previous literature/studies. Some authors referred to the WHO guidelines [18], [19], [20], [21], [22] and CDC guidelines [22], [23], H1N1 epidemic [24], HIV-related surveys [25], [26], SAR-related study [13], and each $\mathrm{MOH}$ guideline in each country [19], [20], [21], [22]. 
Table 3: Determinant factors of COVID-19 preventive measures implementation

\begin{tabular}{|c|c|}
\hline Determinant factors & Authors \\
\hline \multicolumn{2}{|l|}{ Socio-demographic factors } \\
\hline Age & $\begin{array}{l}\text { Lin and Chen 2021; Ngwewondo et al., 2020; Ali et al., } \\
\text { 2021; Almoayad et al., 2021; Aschwanden et al., 2021; } \\
\text { Barakat and Kasemy 2020; Bazaid et al., 2020; Faria } \\
\text { de Moura Villela et al., 2021; Kim and Kim 2020; Turk } \\
\text { et al., 2021; Urbán et al., 2021; Sánchez-Arenas et al., } \\
\text { 2021; Smail et al., } 2021\end{array}$ \\
\hline Gender & $\begin{array}{l}\text { Lin and Chen 2021; Lüdecke and von dem Knesebeck, } \\
\text { 2020; Ngwewondo et al., 2020; Ali et al., 2021; } \\
\text { Almoayad et al., 2021; Bazaid et al., 2020; Faria de } \\
\text { Moura Villela et al., 2021; Kim and Kim 2020; Turk } \\
\text { et al., 2021; Urbán et al., 2021; Sánchez-Arenas et al., } \\
\text { 2021; Smail et al., } 2021\end{array}$ \\
\hline Education level & $\begin{array}{l}\text { Lüdecke and von dem Knesebeck, 2020; Ali et al., } \\
\text { 2021; Barakat and Kasemy 2020; Bazaid et al., 2020; } \\
\text { Turk et al., 2021; Smail et al., 2021 }\end{array}$ \\
\hline Occupation & $\begin{array}{l}\text { Nguyen et al., 2020; Almoayad et al., 2021; Barakat } \\
\text { and Kasemy 2020; Faria de Moura Villela et al., 2021; } \\
\text { Sánchez-Arenas et al., 2021; Turk et al., } 2021\end{array}$ \\
\hline Marital status & Bachok et al., 2021 \\
\hline Ethnicity & Bachok et al., 2021; Smail et al., 2021 \\
\hline Socioeconomic status & Bazaid et al., 2020; Alkhaldi et al., 2021; Ali et al., 2021; \\
\hline Residential area & $\begin{array}{l}\text { Nguyen et al., 2020; Bazaid et al., 2020; Gutu et al., } \\
\text { 2021; Faria de Moura Villela et al., 2021; }\end{array}$ \\
\hline Settlement size & Turk et al., 2021 \\
\hline \multicolumn{2}{|l|}{ Social Psychological Factors } \\
\hline Perceived severity & $\begin{array}{l}\text { Kim and Kim 2020; Sánchez-Arenas et al., 2021; Smail } \\
\text { et al., 2021; Lin and Chen 2021; Nguyen et al., 2020; } \\
\text { Nourmoradi et al., } 2020\end{array}$ \\
\hline Perceived barriers & $\begin{array}{l}\text { Mirzaei et al., 2021; Barakat and Kasemy 2020; } \\
\text { Yehualashet et al., 2021; Ali et al., 2021; }\end{array}$ \\
\hline Perceived benefit & $\begin{array}{l}\text { Mirzaei et al., 2021; Barakat and Kasemy 2020; Kim } \\
\text { and Kim 2020; Nguyen et al., 2020; }\end{array}$ \\
\hline Perceived susceptibility & $\begin{array}{l}\text { Barakat and Kasemy 2020; Yehualashet et al., 2021; } \\
\text { Smail et al., 2021; }\end{array}$ \\
\hline Self-efficacy and Maintenance & $\begin{array}{l}\text { Lin et al., 2020; Mirzaei et al., 2021; Kim and Kim 2020; } \\
\text { Lee et al., 2021; Sánchez-Arenas et al., 2021; Smail } \\
\text { et al., } 2021\end{array}$ \\
\hline Intention and & Lin et al., 2020 \\
\hline Coping planning & Lin et al., 2020 \\
\hline Action planning & Lin et al., 2020 \\
\hline Knowledge about COVID-19 & $\begin{array}{l}\text { Gutu et al., 2021; Kim and Kim 2020; Lee et al., 2021; } \\
\text { Wong et al., 2021; }\end{array}$ \\
\hline \multicolumn{2}{|l|}{ Health status factors } \\
\hline Family health status & Kim and Kim 2020; Wong et al., 2021; Turk et al., 2021 \\
\hline Personal health status & $\begin{array}{l}\text { Kim and Kim 2020; Lee et al., 2021; Sánchez-Arenas } \\
\text { et al., } 2021\end{array}$ \\
\hline \multicolumn{2}{|l|}{ Enabling factors } \\
\hline Lack of governmental push & Ali et al., 2021 \\
\hline Media exposure & Kim and Kim 2020; Gutu et al., 2021 \\
\hline Access to information & Nguyen et al., 2020; Wong et al., 2021 \\
\hline Access to PPE & Nourmoradi et al., 2020; \\
\hline Access to healthcare & Lee et al., 2021 \\
\hline Social support & Kim and Kim 2020 \\
\hline
\end{tabular}

However, few instruments reported their reliability scores [18], [26], [27], [28] [29], [30], [31], [32] while those which did not report their psychometric testing cannot be identified for their instrument reliability. According to Waltz et al. [46], the use of validated measurement tools is needed to reduce measurement errors and incorrect conclusions. Hence, the findings of this review can be used as the foundation to develop a valid and reliable COVID-19 preventive behavior instrument which is cultural-based and psychometrically tested.

Regarding the WHO [47], COVID-19 preventive behaviors include hand washing; cleaning with soap and water or sanitizer, especially after touching a surface in a public place; using masks and gloves; covering the mouth and nose while coughing and sneezing; not touching the face with unclean hands; and social distancing. Based on the use of instruments in articles, all selected studies found that the purpose of preventive measures are to help protect individuals from becoming infected and prevent virus transmission from those who are infected and community preventive measures are in the range of good and poor practice. In addition, other measures were identified in this scoping review, namely immune boosting as well as self-screening and medications

Immune boosting measures are related to consuming diet and lifestyle modification to improve the immune system during the pandemic such as taking vitamins, maintaining a healthy lifestyle, and cooking meat and eggs well. Immune boosting is a part of immune strengthening which is expected to reduce symptoms. On the other hand, some people believe that consuming certain foods such as vitamin C, citrus fruits, garlic, ginger, and honey with warm water, plenty of fluids, boiled water and gargling with saline water may prevent the transmission of COVID-19. Indeed, consuming these supplements may provide symptomatic relief for the common cold; however, no evidence exists for these approaches in the treatment or prevention of COVID-19 [48]. These findings show the importance of immune boosting measures as part of the health education to improve community health literacy that will be seen in COVID-19 preventive behavior adherence.

According to the findings, there are diverse reported preventive behavior attributes. This might be the result of every country having different regulations and recommendations despite the similarity of the preventive strategies. The timeliness, scale and assertiveness of implementation regimes have varied considerably [47]. For instance related to ventilation, proper ventilation has an important role in reducing the transmission of COVID-19 indoors. However, not all studies include ventilation as a component of COVID-19 preventive strategies.

In general, a healthy lifestyle as a component of preventive measures is affected by internal and external factors. The internal and external factors of the selected articles which are related to preventive behaviors can be classified into four categories: socio-demographic factors, social psychological factors, health status factors, and enabling factors. This review article presents the COVID-19 preventive measures as influenced by several factors. In line with Health Belief Model (HBM) theory related to individual readiness in modifying behavior, healthy lifestyle is affected by the perception of oneself [49].

\section{Conclusion}

The aspects of COVID-19 preventive behavior implementation include personal and community preventive measures, immune boosting, and selfscreening/medication. These measures are reported as good and poor practice. In addition, factors related to these measures involving socio-demographic, sociopsychological, health status, and enabling factors. 
Further research needs to be focused on intervention development to improve the adherence of the preventive measures by considering reported determinants factors.

\section{Authors' Contribution}

All authors contributed equally to conceptualization, methodology, article search, data analysis, and writing as well as editing of the manuscript.

\section{References}

1. Naserghandi A, Allameh SF, Saffarpour R. All about COVID-19 in brief. New Microbes New Infect. 2020;35:100678. https://doi. org/10.1016/j.nmni.2020.100678

PMid:32292590

2. World Health Organization. Weekly Operational Update on COVID-19 30 November 2021. Geneva: World Health Organization; 2021.

3. Saladino V, Algeri D, Auriemma V. The psychological and social impact of Covid-19: New perspectives of well-being. Front Psychol. 2020;11:2550. https://doi.org/10.3389/ fpsyg.2020.577684

PMid:33132986

4. Li LZ, Wang S. Prevalence and predictors of general psychiatric disorders and loneliness during COVID-19 in the United Kingdom. Psychiatry Res. 2020;291:113267. https://doi. org/10.1016/j.psychres.2020.113267

PMid:32623266

5. Cao W, Fang Z, Hou G, Han M, Xu X, Dong J, et al. The psychological impact of the COVID-19 epidemic on college students in China. Psychiatry Res. 2020;287:112934. https:// doi.org/10.1016/j.psychres.2020.112934

PMid:32229390

6. Notoatmodjo S. Promosi Kesehatan dan Perilaku Kesehatan. Jakarta: Rineka Cipta; 2012.

7. Shaw R, Kim Y, Hua J. Governance, technology and citizen behavior in pandemic: Lessons from COVID-19 in East Asia. Prog Disaster Sci. 2020;6:100090. https://doi.org/10.1016/j. pdisas.2020.100090

8. Centers for Disease Control and Prevention. Factsheet. Atlanta, Georgia: Centers for Disease Control and Prevention; 2020.

9. World Health Organization. Coronavirus Disease (COVID-19). Geneva: World Health Organization; 2021.

10. Goldman RD, Yan TD, Seiler M, Cotanda CP, Brown JC, Klein EJ, et al. Caregiver willingness to vaccinate their children against COVID-19: Cross sectional survey. Vaccine. 2020;38(48):7668-73. https://doi.org/10.1016/j. vaccine.2020.09.084

PMid:33071002

11. Viswanath A, Monga P. Working through the COVID-19 outbreak: Rapid review and recommendations for MSK and allied heath personnel. J Clin Orthop Trauma. 2020;11(3):500-3. https://doi.org/10.1016/j.jcot.2020.03.014 PMid:32292256

12. Wong J, Goh QY, Tan Z, Lie SA, Tay YC, Ng SY, et al. Preparing for a COVID-19 pandemic: A review of operating room outbreak response measures in a large tertiary hospital in Singapore. Can J Anaesth J Can Anesth. 2020;67(6):732-45. https://doi. org/10.1007/s12630-020-01620-9

PMid:32162212

13. Kim S, Kim S. Analysis of the impact of health beliefs and resource factors on preventive behaviors against the COVID-19 pandemic. Int J Environ Res Public Health. 2020;17(22):8666. https://doi.org/10.3390/ijerph17228666

PMid:33266386

14. LaMorte WW. Behavioral Change Models: The Health Belief Model [Internet]. 2019 Boston University School of Public Health; Available from:https://sphweb.bumc.bu.edu/ottt/mphmodules/ $\mathrm{sb} /$ behavioralchangetheories/behavioralchangetheories2.html [Last accessedon 2021 Sep 04].

15. Jones CL, Jensen JD, Scherr CL, Brown NR, Christy $\mathrm{K}$ Weaver $\mathrm{J}$. The health belief model as an explanatory framework in communication research: Exploring parallel, serial, and moderated mediation. Health Commun. 2015;30(6):566-76. https://doi.org/10.1080/10410236.2013.873363

PMid:25010519

16. Critical appraisal tools [Internet]. Critical Appraisal Tools. Joanna Briggs Institute; Available from: https://jbi.global/criticalappraisal-tools [Last accessed on 2021 Sep 11].

17. Tricco AC, Lillie E, Zarin W, O'Brien K, Colquhoun H, Kastner M, et al. A scoping review on the conduct and reporting of scoping reviews. BMC Med Res Methodol. 2016;16:15. https://doi. org/10.1186/s12874-016-0116-4

18. Lin CY, Imani V, Majd NR, Ghasemi Z, Griffiths MD, Hamilton K, et al. Using an integrated social cognition model to predict COVID-19 preventive behaviours. $\mathrm{Br} J$ Health Psychol. 2020;25(4):981-1005. https://doi.org/10.1111/bjhp.12465 PMid:32780891

19. Bazaid AS, Aldarhami A, Binsaleh NK, Sherwani S, Althomali OW. Knowledge and practice of personal protective measures during the COVID-19 pandemic: A cross-sectional study in Saudi Arabia. PloS One 2020;15(12):e0243695. https:// doi.org/10.1371/journal.pone.0243695 PMid:33306718

20. Gutu B, Legese G, Fikadu N, Kumela B, Shuma F, Mosisa W, et al Assessment of preventive behavior and associated factors towards COVID-19 in Qellam Wallaga Zone, Oromia, Ethiopia:Acommunitybased cross-sectional study. PLoS One. 2021;16(4):e0251062. https://doi.org/10.1371/journal.pone.0251062 PMid:33930102

21. Sánchez-Arenas R, Doubova SV, González-Pérez MA, PérezCuevas R. Factors associated with COVID-19 preventive health behaviors among the general public in Mexico City and the State of Mexico. PLoS One. 2021;16(7):e0254435. https://doi. org/10.1371/journal.pone.0254435 PMid:34297730

22. Almoayad FA, Bin-Amer LA, Mahboub S, Alrabiah AM, Alhashem AM. Preventive practices against COVID-19 among residents of Riyadh, Saudi Arabia. J Infect Dev Ctries. 2021;15(6):780-6. https://doi.org/10.3855/jidc.13175 PMid:34242186

23. Aschwanden D, Strickhouser JE, Sesker AA, Lee JH, Luchetti M, Terracciano A, et al. Preventive behaviors during the COVID-19 pandemic: Associations with perceived behavioral control, attitudes, and subjective norm. Front Public Health. 2021;9:662835. https://doi.org/10.3389/fpubh.2021.662835 PMid:34026716

24. Bachok N, Ghazali AK, Hami R. Knowledge, awareness, attitude and preventive behaviour on the transmission of the pandemic novel Coronavirus among Malaysians. Malays J Med Sci. 
2021;28(2):106-18. https://doi.org/10.21315/mjms2021.28.2.10 PMid:33958965

25. Banda J, Dube A, Brumfield S, Amoah A, Crampin A, Reniers G, et al. Knowledge, risk perceptions, and behaviors related to the COVID-19 pandemic in Malawi. Demogr Res. 2021;44:459-80. https://doi.org/10.4054/DemRes.2021.44.20

26. Yehualashet SS, Asefa KK, Mekonnen AG, Gemeda BN, Shiferaw WS, Aynalem YA, et al. Predictors of adherence to COVID-19 prevention measure among communities in North Shoa Zone, Ethiopia based on health belief model: A crosssectional study. PLoS One. 2021;16(1):e0246006. https://doi. org/10.1371/journal.pone.0246006

PMid:33481962

27. Lin $\mathrm{HC}$, Chen CC. Disease prevention behavior during the COVID-19 pandemic and the role of self-esteem: An extended parallel process model. Psychol Res Behav Manag. 2021;14:123-35. https://doi.org/10.2147/PRBM.S291300 PMid:33603513

28. Mirzaei A, Kazembeigi F, Kakaei $H$, Jalilian M, Mazloomi $S$, Nourmoradi $\mathrm{H}$. Application of health belief model to predict COVID-19-preventive behaviors among a sample of Iranian adult population. J Educ Health Promot 2021;10:69. https://doi. org/10.4103/jehp.jehp_747_20

PMid:34084816

29. Nourmoradi H, Kazembeigi F, Kakaei H, Jalilian M, Mirzaei A. Assessment of knowledge, attitude, and practice toward COVID-19 among a sample of Iranian general population. Open Access Maced J Med Sci. 2021;8. https://doi.org/doi. org/10.3889/oamjms.2020.5094.

30. Ali RAE, Ghaleb AA, Abokresha SA. COVID-19 related knowledge and practice and barriers that hinder adherence to preventive measures among the Egyptian community. An epidemiological study in Upper Egypt. J Public Health Res 2021;8:10. https://doi.org/10.4081/jphr.2021.1943

31. Wong JY, Wai AK, Zhao S, Yip F, Lee JJ, Wong CK, et al. Association of individual health literacy with preventive behaviours and family well-being during COVID-19 pandemic: Mediating role of family information sharing. Int $\mathrm{J}$ Environ Res Public Health 2020;17(23):8838. https://doi.org/10.3390/ijerph17238838 PMid:33261157

32. Barakat AM, Kasemy ZA. Preventive health behaviours during coronavirus disease 2019 pandemic based on health belief model among Egyptians. Middle East Curr Psychiatry. 2020;27(1):43. https://doi.org/10.1186/s43045-020-00051-y

33. Lüdecke $D$, von dem Knesebeck $O$. Protective behavior in course of the COVID-19 outbreak survey results from Germany. Front Public Health. 2020;8:567. https://doi.org/10.3389/ fpubh.2020.572561

PMid:33072712

34. Nguyen NP, Hoang TD, Tran VT, Vu CT, Fodjo JN, Colebunders R, et al. Preventive behavior of Vietnamese people in response to the COVID-19 pandemic. PLoS One. 2020;15(9):e0238830. https://doi.org/10.1371/journal.pone.0238830 PMid:32903286

35. Ngwewondo A, Nkengazong L, Ambe LA, Ebogo JT, Mba FM, Goni $\mathrm{HO}$, et al. Knowledge, attitudes, practices of/towards COVID 19 preventive measures and symptoms: A crosssectional study during the exponential rise of the outbreak in Cameroon. PLoS Negl Trop Dis. 2020;14(9):e0008700. https:// doi.org/10.1371/journal.pntd.0008700 PMid:32886678

36. Alkhaldi G, Aljuraiban GS, Alhurishi S, De Souza R, Lamahewa K, Lau R, et al. Perceptions towards COVID-19 and adoption of preventive measures among the public in Saudi Arabia: A cross sectional study. BMC Public Health. 2021;21(1):1251. https:// doi.org/10.1186/s12889-021-11223-8

PMid:34187425

37. Faria de Moura Villela E, López RV, Sato AP, de Oliveira FM, Waldman EA, Van den Bergh R, et al. COVID-19 outbreak in Brazil: Adherence to national preventive measures and impact on people's lives, an online survey. BMC Public Health. 2021;21(1):152. https://doi.org/10.1186/s12889-021-10222-z PMid:33461508

38. Karijo E, Wamugi S, Lemanyishoe S, Njuki J, Boit F, Kibui V, et al. Knowledge, attitudes, practices, and the effects of COVID-19 among the youth in Kenya. BMC Public Health. 2021;21(1):1020. https://doi.org/10.1186/s12889-021-11067-2 PMid:34053442

39. Lee M, Kang BA, You M. Knowledge, attitudes, and practices (KAP) toward COVID-19: A cross-sectional study in South Korea. BMC Public Health. 2021;21:295. https://doi.org/10.1186/ s12889-021-10285-y

40. Turk E, Čelik T, Smrdu M, Šet J, Kuder A, Gregorič M, et al. Adherence to COVID-19 mitigation measures: The role of sociodemographic and personality factors. Curr Psychol. 2021;1-17. https://doi.org/10.1007/s12144-021-02051-5 PMid:34334989

41. Quandt SA, LaMonto NJ, Mora DC, Talton JW, Laurienti PJ, Arcury TA. COVID-19 pandemic among latinx farmworker and nonfarmworker families in North Carolina: Knowledge, risk perceptions, and preventive behaviors. Int J Environ Res Public Health. 2020;17(16):5786. https://doi.org/10.3390/ijerph17165786 PMid:32785108

42. Urbán R, Paksi B, Miklósi Á, Saunders JB, Demetrovics Z. Non-adherence to preventive behaviours during the COVID-19 epidemic: Findings from a community study. BMC Public Health. 2021;21:1462. https://doi.org/10.1186/s12889-021-11506-0

43. Smail E, Schneider KE, DeLong SM, Willis K, ArringtonSanders R, Yang C, et al. Health beliefs and preventive behaviors among adults during the early COVID-19 pandemic in the United States: A latent class analysis. Prev Sci. 2021;22(8):1013-22. https://doi.org/10.1007/s11121-021-01273-0 PMid:34275054

44. KasI SV, Cobb S. Health behavior, illness behavior and sick role behavior. Arch Environ Health Int J. 1966;12(2):246-66. https:// doi.org/10.1080/00039896.1966.10664365 PMid:5322534

45. Clark C, Davila A, Regis M, Kraus S. Predictors of COVID-19 voluntary compliance behaviors: An international investigation. Glob Transit. 2020;2:76-82. https://doi.org/10.1016/j. glt.2020.06.003 PMid:32835202

46. Waltz CF, Strickland OL, Lenz ER. Measurement in Nursing and Health Research. Berlin: Springer Publishing Company; 2010.

47. World Health Organization. Coronavirus Disease (COVID-19): Masks. Geneva: World Health Organization; 2020.

48. Bucher A, White N. Vitamin C in the prevention and treatment of the common cold. Am J Lifestyle Med. 2016;10(3):181-3. https:// doi.org/10.1177/1559827616629092 PMid:30202272

49. Noghabi AD, Mohammadzadeh F, Yoshany N, Javanbakht S The prevalence of preventive behaviors and associated factors during the early phase of the COVID-19 pandemic among Iranian People: Application of a health belief model. J Prev Med Hyg. 2021;62(1):E60-6. https://doi.org/10.15167/2421-4248/ jpmh2021.62.1.1622

PMid:34322618 